\title{
Dante Bresolin
}

É, para mim, uma honra apresentar a entrevista do Prof. Dr. Dante Bresolin, meu mestre e amigo, à Revista Dental Press de Ortodontia e Ortopedia Facial. Prof. Bresolin é possuidor de uma visão clara, não apenas das questões ortodônticas, mas também das relativas à humanidade de uma forma geral. Estou certo que os leitores da revista lucrarão ao tomar contato com as idéias seguras de uma das pessoas mais sábias da Odontologia brasileira.

Jorge Faber

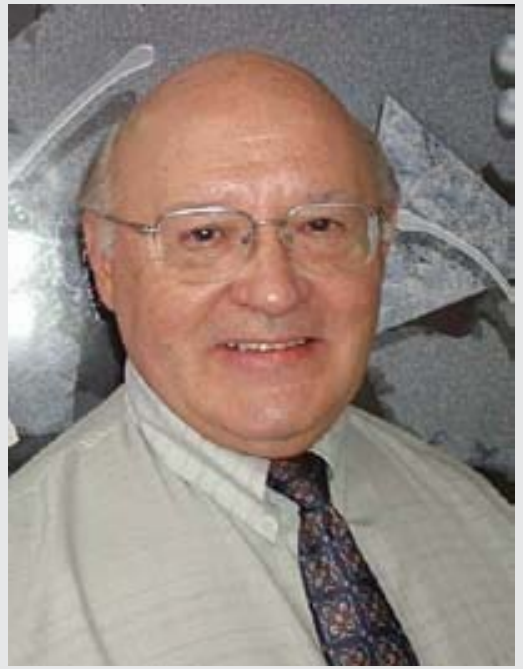

- Mestre em Ciências pela Unicamp e pela University of Washington;

- Doutor em Ortodontia pela UFRJ;

- Professor de Ortodontia da UnB.

1) O seu trabalho sobre respiração bucal em crianças alérgicas e sua relação com 0 desenvolvimento dentofacial, publicado no American Journal of Orthodontics em 1983 ${ }^{1}$ é considerado um marco na literatura ortodôntica. Que características esqueléticas e dentárias foram observadas nestas crianças que as diferenciavam das crianças com padrão respiratório nasal? Marcos Lenza

O trabalho acima citado foi publicado há 22 anos. Naquela época já havia indícios clínicos suficientes para relacionar respiração bucal com má oclusão. Até então havia a idéia de que diferentes obstruções nasais poderiam provocar padrões faciais levemente distintos. Falava-se até sobre uma face adenoidiana. O objetivo da pesquisa foi trabalhar com uma amostragem a mais pura possivel de crianças em crescimento, cuja obstrução nasal fosse a rinite alérgica. Os resultados da avaliação mostraram que, basicamente, os indivíduos portadores de respiração bucal têm faces mais altas, mais estreitas e mais retruídas do que os respiradores nasais. Transversalmente, as abóbadas palatinas são mais altas e mais estreitas, propiciando uma maior tendência a relações dentárias posteriores de topo ou cruzadas. Os principais aspectos dentários compreendem uma acentuação dos trespasses incisais, tanto o vertical quanto o ântero-posterior. As características faciais são realmente dignas de nota: tendência a face alta e estreita, narinas subdesenvolvidas com freqüente hipertrofia dos cornetos nasais e corrimento abundante de secreção nasal, mucosa oftálmica congestionada, olheiras profundas, expressão facial triste, vaga e distante, posição supino da cabeça, com a boca ocupando, verticalmente, a posição do nariz, lábios abertos, sendo o superior curto e o inferior fletido, língua abaixada e ressecamento dentário e gengival. Devido à expressão facial desatenta alguns autores chegam a afirmar que os respiradores bucais têm menor rendimento escolar. A comparação das faces da amostragem da minha investigação, cuja obstrução era a rinite alérgica, com as dos portadores de outras obstruções inflamatórias, como a adenoidiana ou a amigdaliana, ou mesmo obstruções mecânicas, como desvios do septo nasal, mostrou que elas eram muito assemelhadas, daí não se justificar o termo face adenoidiana. Aliás, o fato de que os pacientes com rinite alérgica costumam engolir o muco infectado, um processo conhecido como 
descarga pós-nasal (post-nasal discharge) faz com que a maioria deles desenvolva também adenoidite e/ou amigdalite. E mais, a mesma aparência ocorreu nas faces de macaquinhos em crescimento dos centros de primatologia da Califórnia depois que pesquisadores introduziram por um longo tempo tampões de borracha em suas narinas, obrigandoos a abrir a boca para respirar.

2) Que parâmetros clínicos objetivos podem ser utilizados pelos ortodontistas na identificação de um respirador bucal? Marcos Lenza

Registros mais antigos na literatura sugerem que se pergunte ao paciente se ele respira pela boca ou pelo nariz. É interessante observar como muitos jovens pacientes, ou mesmo suas mães, não sabem responder com segurança essa pergunta. Alguns autores recomendam o uso de chumaços de algodão em frente às narinas para verificar se eles se movem em função da respiração. Ainda outros preconizam o uso de espelhos debaixo e próximos às narinas para detectar eventuais embaçamentos. Ambas as situações mostram que mesmo respeitados autores ortodônticos desconhecem o fato de que existe um ciclo nasal que respeita uma periodicidade. Em função desse ciclo fisiológico, uma das narinas pode estar completamente congestionada enquanto a outra está completamente aberta e, alternadamente, ocorre uma troca dessa situação entre as narinas. Num período intermediário ambas as narinas também podem estar, simultaneamente, num processo de congestão e de descongestão. Qualquer pessoa pode testar em si mesma esse mecanismo fisiológico. Por isso, o parâmetro mais objetivo na identificação de um respirador bucal é simplesmente observar se os lábios estão constantemente fechados ou abertos. Algumas mães de pacientes afirmam, defensivamente, que seus filhos mantêm os lábios abertos, mas respiram pelo nariz. É uma informação ilusória, porque, na verdade, o aspecto "modo de respirar" é secundário em relação ao fator mais importante, como "ter ou não selamento labial". Em 1860 o engenheiro civil e pintor norte-americano George Catlin publicou um livro, fruto de suas observações, que intitulava-se "Feche a sua boca e salve sua vida" (Shut your mouth and save your life ${ }^{2}$ ). O livro alcançou 9 edições sucessivas e hoje Catlin, que nunca foi médico, é o "Pai da Rinologia" norteamericana. Apesar de tudo isso, os ortodontistas continuam a prestar atenção ao modo de respiração, quando deveriam preocupar-se em avaliar se os lábios estão abertos ou fechados. Alguém poderá argumentar que ambos aspectos significam a mesma coisa, porque um é decorrente do outro, mas temos de convir que, para benefício ortodôntico, de nada adianta alguém respirar pelo nariz se os lábios continuam abertos.

3) Apesar da literatura ortodôntica ser contraditória, em sua opinião, até que ponto uma má oclusão Classe II pode ser decorrente da respiração bucal? No livro "Controvérsias atuais em Ortodontia3", coordenado pela Prof ${ }^{a}$ Birte Melsen, há um capítulo específico sobre "Morfologia Dentofacial e Respiração - um século de controvérsias", escrito pelos Profs. Warren e Spalding. Por quê ainda persiste tanta controvérsia em relação a este tema? Marcos Lenza

Más oclusões não são doenças e nem suas existências são monocausais. Dockrell explicou muito bem como variados fatores, incidindo em diferentes épocas, durante um certo tempo, sobre determinados tecidos ou estruturas, podem provocar múltiplos problemas. Assim, uma má oclusão Classe II não pode ser decorrente exclusivamente da respiração bucal. A minha investigação e as de outros autores mostraram que o fator respiração bucal (=ausência de selamento labial) pode coexistir com qualquer tipo de má oclusão e o que ela faz é complicar ainda mais o quadro clínico, principalmente adicionando características esqueléticas mais específicas aos mesmos. Enquanto os profissionais ou pesquisadores continuarem a procurar 
no "modo de respirar" a causa principal, mesmo que com avaliações rinomanométricas, continuará a existir a controvérsia. Mas, quando mudarem o foco de atenção para a presença ou não do selamento labial, creio que muitas das controvérsias deixarão de existir. Essa é a minha convicção no presente momento.

4) Qual um conselho clínico sobre o tratamento de pacientes respiradores bucais que - Sr. gostaria de transmitir aos ortodontistas mais novos, fruto da experiência em Ortodontia que o Sr. adquiriu? Adilson Luiz Ramos

Pacientes ortodônticos com comprometimento respiratório e, freqüentemente, fonoaudiológico, requerem tratamento integrado, seqüencial ou simultâneo, entre os diferentes profissionais envolvidos. Quase sempre o otorrinolaringologista é o primeiro profissional a ser consultado e ele poderá propor um tratamento medicamentoso ou cirúrgico para a obstrução. Infelizmente, após o tratamento otorrinolaringológico, mesmo que o médico ateste que as vias aéreas superiores do paciente estão livres das obstruções, ele não reeduca o paciente para que ele volte a respirar pelo nariz. Em resumo, para o ortodontista continua tudo igual, isto é, o paciente continua sem selamento labial. Nos Estados Unidos pode entrar em cena, neste momento, o mioterapista bucal, que treina o paciente a manter a boca fechada. No Brasil não existe esse profissional e, então, o paciente é referido ao fonoaudiólogo, um profissional com grande capacitação para resolver problemas auditivos e da fala, mas poucos recursos e habilidades mioterápicas. É comum que, após algumas consultas, o paciente ou o fonoaudiólogo desistam da reeducação respiratória. Então, e quase sempre, o ortodontista recebe uma carta do fonoaudiólogo informando que o paciente não "automatizou" os exercícios e ele, o fonoaudiólogo, sugere que o ortodontista coloque um impedidor ou uma grade lingual. Assim, o paciente retorna ao ortodontista ainda sem selamento labial e representando um grande desafio: como o ortodontista tratará uma má oclusão em que o paciente ainda respira pela boca e projeta a língua? Essa é a minha realidade clínica e creio que a de muitos dos meus colegas. Como quase todos os pacientes estão em fase de crescimento, urge iniciar o tratamento ortodôntico e esperar que, ao final do mesmo, então com uma anatomia facial mais favorável, os pacientes voltem a exercitar o selamento labial. $\mathrm{Na}$ adolescência os eventos rinológicos obstrutivos são mais espaçados e menos intensos, a compreensão, a motivação e a vaidade do pacientes estão mais presentes. É possível que, dentro desta nova realidade, a reeducação respiratória seja possível e mais permanente. Se existe um conselho a ser passado aos ortodontistas mais novos é o de que compreendam que os respiradores bucais requerem tratamento multiprofissional, mas que, mesmo assim, não podem esperar indefinidamente pelo sucesso desses outros profissionais, pois provavelmente ele não ocorrerá a contento e a tempo.

\section{5) Após anos de experiência clínica, qual o seu parecer quanto aos tratamentos precoces dos pacientes com ângulo do plano mandi- bular aumentado e mordida aberta anterior, utilizando, por exemplo, bite-block associado à mentoneira vertical (de uso noturno)? O Sr. segue algum protocolo específico para estes tipos de casos? Adilson Luiz Ramos}

Não, não tenho protocolo específico para o tratamento de nenhuma má oclusão. Ao longo da minha vida profissional aprendi que é verdadeira a assertiva dos meus professores de que não existe um "livro de receitas" para ser utilizado no consultório, como se usa numa cozinha. É uma grande verdade a afirmação de que "cada caso é um caso". Desde 1980 adoto o protocolo de ordem geral que aprendi na University of Washington. De acordo com ele, cada má oclusão é avaliada esqueleticamente nos planos vertical, ântero-posterior e transversal, bem como suas características dentárias e interações diversas. Cada problema 
recebe uma nota de 0 a 10 e são propostas soluções em potencial. Os problemas mais severos e o equilíbrio das diferentes soluções em potencial vão gerar os objetivos do tratamento e, em seguida, o plano de tratamento e a sua execução. Esse processo todo está minuciosamente detalhado no livro "Ortodontia Contemporânea" do Prof. William Proffit, também um ex-aluno da University of Washington, que segue fielmente e preconiza o processo que aprendeu.

6) Qual o seu pensamento sobre o reconhecimento da Ortopedia Funcional dos Maxilares como uma especialidade odontológica? Orlando Ayrton de Toledo

Acredito que os métodos da Ortopedia Funcional dos Maxilares são muito importantes, mas limitados na sua capacidade de prover soluções para todas as necessidades dos pacientes com más oclusões. Um profissional treinado somente em Ortopedia Funcional dos Maxilares terá muita dificuldade em concluir satisfatoriamente os seus casos. Se não for treinado em aparelhos fixos, terá que concluir seus tratamentos ortodônticos com aparelhos removiveis, um processo completamente ultrapassado. Por isso, a Ortopedia Funcional dos Maxilares não se sustenta como uma especialidade. No meu entender ela é basicamente uma técnica e não uma especialidade. Do mesmo modo, a palavra Ortodontia descreve muito pobremente o escopo das suas potencialidades, que transcendem a simples movimentação dentária. $\mathrm{O}$ tratamento ortodôntico bem executado, presta também atendimento ortopédico mecânico. Acredito que, se prevalecer o bom-senso, dentro de alguns anos os futuros ortodontistas e os ortopedistas funcionais pertencerão a uma especialidade da Odontologia que será chamada de Ortopedia Facial e eles provavelmente serão chamados de ortopedistas faciais. Ao longo dos anos a American Association of Orthodontists tem dado uma grande contribuição neste sentido, gradativamente alterando o nome da sua revista. E para o treinamento completo desses futuros profissionais as universidades terão de ensinar técnicas ortopédicas funcionais, técnicas ortopédicas mecânicas e movimentação dentária. Espera-se que nenhum profissional que advir dessa nova educação pensará que é melhor ou superior aos outros, pois já não existirão os "outros", e também não terá que sofrer qualquer tipo de constrangimento sobre a qualidade do seu trabalho.

7) Qual a sua opinião sobre a possibilidade de se criar uma prova para exercício da Odontologia à semelhança da prova da Ordem dos Advogados do Brasil? Jorge Faber

Talvez, há alguns anos atrás, não fosse realmente necessária a realização de uma prova de qualificação odontológica imediatamente após a graduação. Mas, com a atual vergonhosa proliferação de Cursos de Odontologia, com a existência até de faculdades que, sabidamente, vendem vagas a quem as pode pagar, caiu muito a qualidade média do cirurgião-dentista que ingressa ou que é egresso de algumas faculdades. Em breve a prova de qualificação se tornará uma real necessidade, tal qual já é realizada há muitos anos nos Estados Unidos. Mas até isso será difícil de ser implementado, pois creio que muitos dentistas, tal como acontece entre muitos bacharéis de Direito, não conseguirão sequer entender as perguntas da prova, tal o despreparo que têm na lide com o idioma pátrio. Basta ver que até os cartazes dos melhores congressos odontológicos do Brasil, coordenados pela elite da nossa profissão, são cheios de crases e hífens que não deveriam existir, ou faltam as crases e hífens que deveriam existir. Muitos dentistas nunca leram um bom livro e a cultura geral deles é mínima. Penso que além de se aplicar uma prova ao final da graduação, deve ser aperfeiçoada a seleção dos que concorrem às vagas das faculdades.

\footnotetext{
8) Como o senhor vê a proliferação dos cursos de Especialização em Ortodontia em nosso país? Orlando Ayrton de Toledo
}

Vejo o fato com muita preocupação. Um país 
com população em escala continental, como o Brasil requer a existência de um número também grande de ortodontistas. Mas o que está acontecendo é uma irresponsável colocação no mercado de legiões de ortodontistas preparados, ou melhor, despreparados, pelos mais diferentes tipos de cursos de especialização, meros repetidores de conceitos e técnicas, sem nenhum academicismo ou geração de novos conhecimentos, burlando a lei e a boa-fé dos incautos alunos. Não há um leigo que não note que há um total descontrole nos caminhos da profissão. Os comentários malévolos sobre esses "novos ortodontistas" estão por toda a parte. E os arquivos dos Conselhos Regionais de Odontologia estão locupletados de processos éticos movidos por pacientes insatisfeitos. Alguns colegas de nobres propósitos aqui ou ali tentam resistir oferecendo cursos de especialização de boa qualidade, mas os gananciosos seguidores do mal são em muito maior número. Por outro lado, também não se verifica nenhum gesto concreto das autoridades superiores da educação no Brasil, ou mesmo dos órgãos superiores da especialidade, que possa frear o vergonhoso caos que se instalou. Sou professor de graduação há 31 anos. Na tradicional aula de "educação ortodôntica" que eu sempre ministrei e continuo a ministrar, ensino que, dentro da minha maneira de ver, só existem duas maneiras corretas de algum dentista se especializar em Ortodontia: nas universidades brasileiras ou nas universidades estrangeiras. E que hotéis, motéis, salões paroquiais, clínicas particulares, associações de classe, sindicatos, congressos odontológicos ou ortodônticos, fazendas, sítios, prédios comerciais e outros que tais não se prestam à formação de especialistas em Ortodontia. Não tenho nada contra a que se usem tais locais, mas para cursos informativos, de aperfeiçoamento, de extensão ou ensino de novas técnicas, destinados exclusivamente a quem já é, reconhecidamente, um profissional plenamente especializado por alguma faculdade ou universidade e devidamente registrado como especialista no conselho regional de sua jurisdição. Infelizmente, muitos profissionais destacados da nossa especialidade emprestam seus nomes a essas atividades formativas não recomendáveis, mas altamente lucrativas.

\section{9) Atualmente estamos assistindo a uma onda de comportamentos antiéticos e tam- bém de pessimismo em relação ao futuro da Ortodontia como profissão no nosso país. a) De quem é a culpa? Claudenir Rossato}

Respondo a esta "pergunta que não quer calar" com a argumentação de que os culpados são os próprios ortodontistas. Como assim? Bem, não podemos culpar os odontopediatras, os endodontistas, os periodontistas ou os outros colegas nossos. Eles não são ortodontistas, não praticam e nem ensinam Ortodontia. E os ortodontistas? Ah, ao longo dos anos, eles foram perdendo o orgulho de serem seguidores do ínclito Edward H. Angle. Os verdadeiros valores profissionais foram se dissipando e se misturando com o recôndito instinto selvagem de obter fortuna. Aos poucos, as outrora brilhantes medalhas foram sendo preteridas pelas sonantes moedas e, nas últimas décadas, ficou mais promissor acumular riqueza vendendo a ilusão de ensinar do que praticar a especialidade. Também ficou mais fácil enriquecer rapidamente montando clínicas que oferecem serviços a preços irrisórios, mas que, ou não resolvem nada ou criam iatrogenias de todos os tipos. E os ortodontistas ainda com alguma reserva moral? Qual é a culpa deles? Bem, pode-se dizer que, por comodismo ou receio de se exporem e emitirem opiniões, ficam calados, omitem-se de acusar e, com essa atitude, favorecem a proliferação dos malfadados cursos "caçaníqueis". E os cursos de especialização de algumas faculdades privadas, como eu preconizo, estão isentos de alguma culpa? Nada disso. Com a conivência da Capes e do CFO, que sofrem de miopia crônica e pouco vêem, inúmeras faculdades privadas espalham tentáculos por todo o Brasil, aliciando alunos, alguns inocentes-úteis e outros nem tão inocentes. Aqui mesmo, em Brasília, próximas do poder central, 
inúmeras sucursais de faculdades de outros estados montaram cursos de especialização em Ortodontia em prédios comerciais, em endereços que bem condizem com os seus escusos objetivos.

\section{b) Que esperança podemos depositar nos} órgãos responsáveis pela defesa da especialidade? Claudenir Rossato

A Ortodontia sempre foi, continua e continuará sendo a mais bela especialidade da Odontologia. Ela alia muita ciência com uma pitada de arte de modo muito particular. A sua prática ideal requer uma visão ampla da face, da dentição e dessa qualidade única ao ser humano, o sorriso. Com certeza a Ortodontia tem um futuro promissor e brilhante. Ele será atingido na medida em que os atuais e próximos dirigentes da nossa especialidade, das nossas associações, conselhos regionais e federal conseguirem reconhecer e extirpar dos seus meios os elementos perniciosos que com eles convivem de modo despudorado. E eles existem. Pertencer a um órgão superior da especialidade e ao mesmo tempo ministrar aulas em cursos espúrios não é um pecado venial. É um pecado mortal para a Ortodontia. Infelizmente eles são cometidos todos os dias. Por isso eu sou mais um dos pessimistas que não acreditam que as coisas melhorarão em curto prazo, pelo menos no que me resta de vida.
Adilson Luiz Ramos

- Mestre (FOB-USP) e Doutor (UNESP - Araraquara) em Ortodontia.

- Professor Adjunto do Departamento de Odontologia da Universidade Estadual de Maringá.

\section{Claudenir Rossato}

- Mestre e Doutor em Ortodontia pela FOB-USP.

- Professor Associado da UEL - Londrina.

\section{Marcos Lenza}

- Professor Titular de Ortodontia da Faculdade de Odontologia da Universidade Federal de Goiás.

- Doutor em Ortodontia pela Universidade de Nebraska - EUA.

\section{Orlando Ayrton de Toledo}

- Professor Emérito de Odontologia da Universidade de Brasília.

- Professor do Programa de Pós-Graduação em Ciências da Saúde da Universidade de Brasília.

Jorge Faber

- Doutor em Biologia - Morfologia, Laboratório de Microscopia Eletrônica da Universidade de Brasília

- Mestre em Ortodontia pela Universidade Federal do Rio de Janeiro

- Clínica privada focada no atendimento de pacientes adultos.

\section{REFERÊNCIAS}

1. BRESOLIN, D et al. Mouth breathing in allergic children: its relationship to dentofacial development. Am J Orthod Dentofacial Orthop, St. Louis, v. 83, no. 4, p. 334-349, 1983.

2. CATLIN, G. Shut your mouth and save your life. 9th. ed. London: Kegan Paul, Trench, Trübner, 1891.
3. WARREN, D.; SPALDING, P. M. Dentofacial morphology and breathing: a century of controversy. In: MELSEN B. Current Controversies in Orthodontics. 1st ed. Chicago: Quintessence, 1991. p. 45-76.

4. PROFFITT W R. Ortodontia contemporânea. 3. ed. Rio de Janeiro: Guanabara Koogan, 2000. 